2. Jefferson T, Del Mar C, Dooley L, et al. Physical interventions to interrupt or reduce the spread of respiratory viruses: systematic review. BMJ 2009; 339:b3675.

3. Jefferson T, Foxlee R, Del Mar C, et al. Interventions for the interruption or reduction of the spread of respiratory viruses [review]. Cochrane Database Syst Rev 2007;(4):CD006207.

4. Loeb M, Dafoe N, Mahony J, et al. Surgical mask vs N95 respirator for preventing influenza among health care workers: a randomized trial. JAMA 2009;302: doi:10.1001/jama.2009.1494.

For the full letter, go to: www.cmaj.ca/cgi/eletters/cmaj.109-3066v1\#217416

DOI:10.1503/cmaj.109-2039

\section{Medical school admissions}

Re: "Mission impossible: the quest for medical school." If the author is suggesting that more medical student slots are required, I would agree. If the author is suggesting that successful non-GTA applicants to these two medical schools are not as "bright" as unsuccessful applicants from the GTA, I would like to see some evidence to support his claim.

\section{Mark Otto Baerlocher}

University of Toronto, Toronto, Ont.

\section{REFERENCE}

1. Joel Warsh J. Dispatch from the medical front Mission impossible: the quest for medical school. CMAJ 2009;181:E166.

For the full letter, go to: www.cmaj.ca/cgi/eletters /181/8/E166\#220034

DOI:10.1503/cmaj.109-2040

\section{Social pain and opioid use}

Re: "Opioid prescribing challenges doctors." Increased narcotic prescribing may not be the primary reason for the rise in the street use of these drugs. There may be a common underlying factor - an increase in social pain. The use of functional magnetic resonance imaging reveals that social rejection hurts just as much as physical pain. ${ }^{2}$ As a GP who specializes in treating emotional pain, I can verify that this is definitely on the rise. As more people lose their jobs or fear losing them, as more young people despair of any meaningful future, as life becomes harder and social supports disappear, human pain increases and so does the need for relief. I have found that distressed individuals and families request less pharmacological analgesia when they get more social support. Unfortunately, social policy is going in the opposite direction. As more people are burdened with overwhelming stress, we will see a greater demand for legal and illegal opioids.

Susan M. Rosenthal MD

Private practice, Guelph, Ont.

\section{REFERENCES}

1. Silversides A. Opioid prescribing challenges doctors. CMAJ 2009;181:E143-44.

2. Eisenberger, NI, Lieberman, MD, Williams KD Does rejection hurt? An fMRI study of social exclusion. Science 2003;302:290-92.

For the full letter, go to: www.cmaj.ca/cgi/eletters /181/8/E143\#223919

DOI:10.1503/cmaj.109-2044

\section{Correction}

A news article on painkiller guidelines stated that oxycodone is "twice as addictive as morphine," after several interviewees expressed that personal belief. However, that belief does not appear to be backed up by any research studies. The CMAJ apologizes for the error.

\section{REFERENCE}

1. Silversides A. Regulatory colleges to set painkiller guidelines. CMAJ 2009; 181:464-65.

DOI:10.1503/cmaj.109-2045

\section{Letters to the editor}

In submitting a letter, you automatically consent to have it appear online and/or in print. All letters accepted for print will be edited by $C M A J$ for space and style. Most references and multiple authors' names and full affiliations will appear online only. (The full version of any letter accepted for print will be posted at cmaj.ca.)

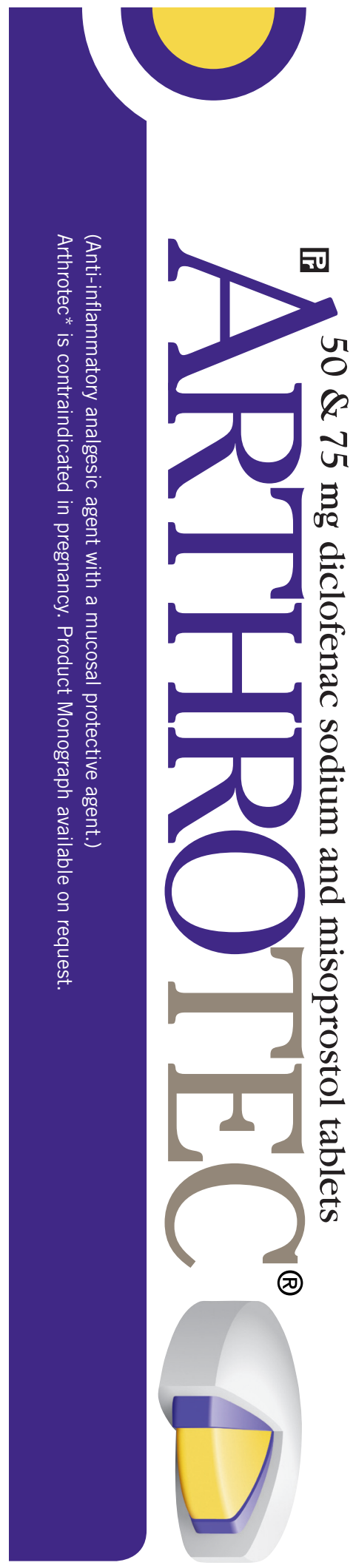

